\title{
Ensuring Seismic Safety of Underground Mines During Blasting Operations in Combined Surface-Underground Deposit Development
}

\author{
Aleksey Novinkov ${ }^{1,2}$, Sergey Protasov ${ }^{1,2 *}$, and Pavel Samusev ${ }^{2}$ \\ ${ }^{1}$ Novation Company «KUZBASS-NIIOGR», 650054, Kemerovo, 4A, Pionerskii blvd, Russian \\ Federation \\ ${ }^{2}$ T.F. Gorbachev Kuzbass State Technical University, 650000 Kemerovo, 28, Vesennaya st, Russian \\ Federation
}

\begin{abstract}
At present, there are no standard methods for assessing seismic safety of underground mines during blasting on the earth's surface. The need for such assessments arises when underground mines are located near open-pit coal mines, when the mine fields development is continued into the open pit, and when open surface coal mines use highwall miners. The issues of assessing seismic safety can be complicated by the lack of experimental data on vibration parameters, for example, if the answer is already required at the stage of new mines designing. The paper also provides an analysis of experimental data, including the results of monitoring the state of underground mines during seismic impacts of varying degrees of intensity. It is shown that the spread of the observed PPV, at which local damage or deformation of the underground mines has taken place, attains high values. In the absence of such data for underground mines in specific mining and geological conditions, it is recommended that the maximum allowable PPV vпр be assigned taking into account the class of underground mines and the type of support. At the same time, it is noted that the recommended ипр values given in the literature relate to the openings that were driven in the solid without geological disturbances and anomalies; not deviating from regulatory requirements regarding the state of workings; in the absence of danger of groundwater breakthrough; in the absence of danger of gas-dynamic phenomena, and other negative factors. If this is not the case, according to the requirements of the Federal norms and rules of industrial safety, the seismic safety distance should be increased by 2 times. This requirement is equivalent to multiplying the maximum permissible vibration velocity by a decreasing coefficient $k=2 b$, where the power of two is the regression parameter $\mathrm{b}$ obtained from the experimental data processing.
\end{abstract}

\section{Introduction}

The issue of ensuring the seismic safety of underground mines that get into the seismic action zone of blasting at open surface mines (open pits and quarries) that conduct open pit

\footnotetext{
${ }^{*}$ Corresponding author: firma@kuzbass-niiogr.ru
} 
mining on the surface arises quite often, for example, when underground mines are located near coal open surface mines, when underground mine fields are finished by open surface mining, when open surface mines are using high wall miners, etc.

Russian regulatory documents in the field of industrial safety [Federal rules and regulations in the field of industrial safety "Safety rules for blasting operations" (2014)] do not provide methods for assessing seismic hazard for underground mines during blasting on the earth's surface. Other regulatory documents, both of the Russian Federation and other countries, related to seismic safety during blasting operations [1-4] are not applicable to underground mines.

Despite the fact that there is a large number of studies related to the assessment of the seismic safety of underground mines during blasting on the earth's surface, the data obtained are often contradictory and not always suitable for practical use. As a rule, most studies use the inequality of the form $\mathrm{v} \leq \mathrm{V}_{\max }$ as a criterion for seismic safety, where $\mathrm{v}$ is the PPV, vпр is the maximum allowable PPV for underground mines of a given type. Using this criterion, the task of ensuring seismic safety is reduced to the successive solution of two problems: forecasting with a given non-exceedance probability of the PPV and assigning the maximum allowable PPV at which the safety of the mine workings is guaranteed with a given probability.

\section{Justification of methodological approaches to assessment of large-scale surface blasting seismic impact on underground mines}

To solve the first problem, i.e. forecasting the peak vibration velocity, a method based on regression analysis of a cloud of experimental data is quite successfully used $[5,6]$. To predict the PPV $v$ during blasting, an expression of the following form is used:

$$
v=K \cdot S D^{b}
$$

where $S D$ is a scale distance (a parameter that depends on the distance to the protected object, as well as on the explosive weight in the group of charges blasted conditionally simultaneously); $K, b$ are the coefficients determined experimentally. In the practice of blasting in Russia, the expression used to determine the reduced distance is as follows:

$$
S D=\frac{D}{\sqrt[3]{Q}}
$$

where $D$ is the actual distance from the blast area (as a rule, from its border) to the protected object; $Q$ is the maximum design explosive weight for a group of charges to be blasted conditionally simultaneously. When designing large-scale industrial blasting, the maximum explosives weight can be taken as Q within any 20-ms sliding window. Note that to determine the scale distance $S D$ other expressions can be used in foreign regulatory documents, for example, $S D=\frac{D}{\sqrt{Q}}$, at the same time, $Q$ can be determined by 8 -ms sliding window. As it is shown in [5], the type of expression for determination of $S D$, as well as the length of the sliding window $-20 \mathrm{~ms}$ or $8 \mathrm{~ms}$ - don't matter, what is changing is only the values of coefficients $K, b$ in expression (1).

Usually, expression (1) is linearized to:

$$
\lg (v)=a+b \cdot \lg S D+t \cdot S E
$$

where summand $t \cdot S E$ takes into account the shift of the calculated regression line to the upper boundary of the confidence interval, while $t$ is the quantile of the given Student distribution level for $n-2$ degrees of freedom ( $\mathrm{n}$ is the number of observations); $S E=$ $\sqrt{\frac{\sum_{i=1}^{n}\left(\lg \left(v_{i}\right)-\lg \left(\hat{v}_{i}\right)\right)^{2}}{n-2}}$-is a standard error of regression, here $\hat{v}_{i}$ and $v_{i}$ are predicted by regression and observed values of vibration velocity in the $i$-th point respectively. 
To reliably predict the PPV, seismic vibrations from 8 to 10 blasts are recorded. Usually, when assessing the seismic effect of industrial explosions on buildings and structures of the surface facilities, 10 to 20 records of seismic vibrations are registered per each explosion. The total sample size from the values of the maximum vibrational velocities required for the forecast with a $95 \%$ non-exceedance probability is 75 to 85 points. However, this most frequently used level of probability corresponds to the likelihood of occurrence in the buildings of the surface structures of light damage such as thin cracks in the plaster and the brickwork mortar, chipping of small pieces of the plaster, and it is clearly insufficient to predict deformations and damage in the mine workings, which are characterized by completely different types of limit states. The practice of predicting the PPV in underground mine workings caused by blasts on the earth's surface shows that in this case the forecast probability should be increased to a level of at least $98 \%$, i.e. in expression (3), a quantile of the level of 0.98 should be used. Such non-exceedance probability is used, for example, in rating the values of snow and wind loads in structures design $[7,8]$. The average repetition period of the rated values of snow and wind loads is 50 years and it approximately corresponds to the average period of operation of ordinary buildings and structures. Approximately the same periods of operation are planned for the main underground mines and open surface mines. As a result, an increase in the required level of probability should be accompanied by an increase in the sample size to 200 points. If it is impossible to provide the necessary amount of experimental data, this should be taken into account in the regression analysis when determining the upper boundary of the confidence interval.

The second task - the assignment of the maximum allowable PPV for underground mines - is characterized by a higher level of estimation uncertainty. To select the maximum allowable PPV for underground mines, one can use recommendations in [9]. According to [9], safe seismic distance $D$ during blasts on the earth surface is determined as $D=K \sqrt[3]{Q_{d}}$, where $Q_{d}$ is the charge weight per delay (weight of charge in a group of charges exploding simultaneously), $\mathrm{kg}$, and $K=\left(\frac{K_{1} K_{2} K_{5}}{V_{\mathrm{B}} K_{3} K_{4}}\right)^{1 / 2}$ is an overall coefficient taking into account blasting conditions, rock strength, class of the underground openings and support type; $v_{\max }$ is the maximum allowable PPV, $\mathrm{cm} / \mathrm{s} ; K_{1}$ is a coefficient taking into account strength of blasted rock; $K_{2}$ is a coefficient taking into account the amount of exposed surfaces of the blasted rock (at conventional blasting $K_{2}=1,0$; when blasting without a compensatory slot, i.e. in the conditions with one exposed surface, $K_{2}=3,0$ ); $K_{3}$ is a coefficient taking into account the change in the allowable PPV depending on the strength properties of the rock at the location of the workings; $K_{4}=1,0 \ldots 3,0$ is a coefficient taking into account the type of support with $K_{4}=1,0$ corresponding to a mine openings without support, and $K_{4}=3,0$ corresponding to a mine working with a steel arch support; $K_{5}<1,0$ is a coefficient taking into account the attenuation of surface waves in the depth of the rock strata. Since $K_{5}$ is applied only for distances $\geq 30 \sqrt[3]{Q_{d}}$, i.e. in a far-distance area, this coefficient is taken equal to 1,0 .

Thus, the seismic safe distance according to [9] for underground workings can be written as:

$$
D=\left(\frac{K_{1} \cdot K_{2}}{V_{\max } K_{3} K_{4}}\right)^{1 / 2} \sqrt[3]{Q_{d}}
$$

Expression (4) can be written in the usual form of a safety criterion similar to the inequality $v \leq v_{\text {пр }}$ :

$$
\frac{K_{1} \cdot K_{2}}{K_{3}}\left(\frac{D}{\sqrt[3]{Q_{d}}}\right)^{-2} \leq v_{\max } \cdot K_{4}
$$

Thus, the factor $\frac{K_{1} \cdot K_{2}}{K_{3}}$ and the power $=-2$ correspond to the seismic coefficient $K$ and the coefficient of reducing of PPV with distance $b$ from expression (1), which can be clarify 
as a result of experimental studies taking into account the required forecast probability. It is proposed to determine the maximum allowable PPV $v_{\max }$ depending on the class of the underground mine and its service life, while the allowable PPV, for example, for first-class underground mine with a service life of more than 10 years, are set at $60 \mathrm{~mm} / \mathrm{s}$. The values of allowable PPV given in [9] are comparable with the data in [10].

It should be noted that the values of maximum allowable PPV given in the literature for underground workings have a rather large range of recommended values. Thus, for example, according to [11], rock fall was observed in the tunnel and adjacent galleries at vibration velocity of $12 \mathrm{in} / \mathrm{s}(305 \mathrm{~mm} / \mathrm{s})$. There are also six-year data based on observations of the underground cavity of the Dwarshak Dam (Idaho, USA) during blasting in granite massif above it [11, 12 by reference from [11]]. For the entire time of observation, only one case of the fall of one or two pieces at a fixed PPV of $5 \mathrm{in} / \mathrm{s}(127 \mathrm{~mm} / \mathrm{s})$ was recorded. The maximum vibration velocities during individual blasts reached $10 \mathrm{in} / \mathrm{s}(254 \mathrm{~mm} / \mathrm{s})$. The blasts were conducted with a gradually decreasing roof thickness, with a residual roof thickness being $30 \mathrm{ft}(9.1 \mathrm{~m})$. During the entire time of blasting, the vault arch rose by 16 $\mathrm{mm}$ due to its relaxation during extraction of the rock above it. In some studies, the maximum permissible vibration velocity for underground workings at the level of $2 \mathrm{in} / \mathrm{s}$ (50 $\mathrm{mm} / \mathrm{s}$ ) is postulated. The results of studies of underground workings during blasts on the surface at the Uchalinsky ore mine are presented. According to these data, rock sloughing from the ribs of the workings was observed at PPV from 8.5 to $9.5 \mathrm{~mm} / \mathrm{s}$, rock falls were observed at vibration velocities from $8.5 \mathrm{~mm} / \mathrm{s}$ to $21.0 \mathrm{~mm} / \mathrm{s}$, and opening of fractures was observed at $9.7 \mathrm{~mm} / \mathrm{s}$ of velocity. However, no quantitative estimates of the damage scope are given.

The maximum allowable PPV for mine shafts, main crosscuts, galleries, and slopes vary from $200 \mathrm{~mm} / \mathrm{s}$ to $550 \mathrm{~mm} / \mathrm{s}$ (depending on the category of seismic activity of the rock in which the workings are driven) and from $300 \mathrm{~mm} / \mathrm{s}$ to $750 \mathrm{~mm} / \mathrm{s}$ - for other mine workings.

The value of the adopted maximum allowable PPV needs to be evaluated separately from the point of view of its effect on the deformation of the cross-section of underground openings. In [11], the results of observations of the cross-section deformations in underground openings over several months of 1974 to 1975 are presented. During this period, observation data on deformations of underground mine workings caused by 31 blast in a nearby quarry were obtained. Both the mine and the quarry were involved in coal mining. The total mass of explosives (a mixture of ammonium nitrate with diesel fuel) on the sections to be blasted ranged from 1,250 to $51,400 \mathrm{lbs}(567$ to $23,315 \mathrm{~kg})$. All the blasts were short-delayed with deceleration intervals of 9,17 , and $25 \mathrm{~ms}$. In total, 4 to 11 (maximum 20) series were used. The depth of the blast-holes ranged from 10 to $40 \mathrm{ft}$ ( 3 to $12 \mathrm{~m}$ ). The weight in the series ranged from 276 to $12,400 \mathrm{lbs}(125$ to $5,625 \mathrm{~kg})$. The blasting frequency ranged from 1 to 2 blasts per week, up to 2 blasts per day. All the blasts were scheduled and performed in the conditions of a working enterprise. The scale distances $S D=\frac{D}{\sqrt[3]{Q}}$ from the deformation registration points to the boundary of the blasting block ranged from 4,7 to $85,5 \mathrm{~m} / \mathrm{kg}^{1 / 3}$. At the same time, deformations were continuously recorded by three fixed drum-type tensiometers, and the change in the distance between the floor and the roof of a mine tunnels was also measured at 23 specially prepared points using a special Philadelphia levelling rod. At the points of installation of fixed tension-meters with continuous recording of deformations, seismometers were also installed that recorded the vibration velocity resulted from industrial blasts on the day surface. Maximum PPV determined according to the

rule $v=\sqrt{v_{x}^{2}+v_{y}^{2}+v_{z}^{2}}$ ranged from 1,6 to $444,5 \mathrm{~mm} / \mathrm{s}$, and the number of records with peak vibration velocities over $50 \mathrm{~mm} / \mathrm{s}$ was not less than 18 . The results of the study showed that two of the three fixed tensiometers with a continuous recording function did 
not record deformations of the underground mine working cross-section. The third tensiometer, which worked for $70 \%$ of the total time of the observations, showed both an increase and a decrease in the distance between the floor and the roof of the working, and each change in distance was quite abrupt and ranged from 0,01 to 0,03 in $(0,254$ to 0,762 $\mathrm{mm}$ ). The total deformation of the cross-section of the mine working in the form of a roof subsidence accumulated over the observation period was 0,1 in $(2,54 \mathrm{~mm})$. Roof deformations at the remaining 23 points did not exceed $0,002 \mathrm{ft}(0,61 \mathrm{~mm})$.

It appears that the maximum allowable PPV given in [9] adequately correspond to the goals of ensuring seismic safety. But it should be noted that the indicated values of permissible vibration velocities should be attributed to the workings that were driven in the rock strata free of any geological disturbances and anomalies; not deviating from regulatory requirements regarding the state of mine workings; in the absence of danger of groundwater breakthrough; in the absence of danger of gas-dynamic phenomena, and other similar negative factors. Should there be any geological disturbances, deviations from regulatory requirements regarding the state of mine workings, danger of groundwater breakthrough, danger of gas-dynamic phenomena, and other similar negative factors, according to the requirements of the Federal rules and regulations [1], the seismic-safe distance should be increased by 2 times. This requirement is equivalent to multiplying the maximum allowable vibration velocity by a decreasing coefficient $\mathrm{k}=2^{\mathrm{b}}$, where the power of two is the regression parameter $b$ obtained from the experimental data.

\section{Conclusion}

The practical significance of the proposed technique for ensuring the seismic safety of underground workings during blasting on the earth's surface is that it makes it possible to take into account the features of blasting technology, as well as the geological and hydrogeological conditions of a particular deposit by adjusting the regression to experimental data. In addition, the statistical approaches used in the technique make it possible to confirm with the target reliability the possibility of using a specific regression model or, conversely, abandon it.

\section{References}

1. GOST R 52892-2007 (2008)

2. OSM Blasting Perfomance Srtandards. 30 Sec. 816.67

3. BS 7385-2:1993 (1993)

4. DIN 4150-3:1999 (1999)

5. A. G. Novinkov, S. I. Protasov, A. S. Gukin, Proc. of 7-th World conference on explosives and blasting, II (2013)

6. A. G. Novinkov, S. I. Protasov, P. A. Samusev, A. S. Gukin, J. of Mining Sc. 51, 5 (2015)

7. EN 1991-1-3:2005 (2005)

8. EN 1991-1-4:2005 (2010)

9. V. L. Baron, V.A. Belin, M. I. Gannopolsky, Guidelines for the determination of safe distances in the manufacture of blasting operations on the earth's surface. Guidelines for determining the radii of hazardous zones of seismic activity of blasts, conducted on the Earth's surface (Nedra, Moscow, 2011) 
10. D. E. Jensen and others. Final Report N408741, US Dept. of Interior, Bureau of Mines (1979)

11. C. O. Faris. ASCE, 1, 159-160 (1971)

12. Ch. H. Dowding, Blast vibration monitoring and control (Springer, Berlin, 1985)

13. N. R. Draper, H. Smith, Applied regression analysis (Springer, Berlin, 1998) 